patients reach adequate compliance at their first review, a minority may need numerous reviews until adequate treatment is achieved, and one in five never achieve adequate CPAP compliance. A significant proportion of patients remain under review a decade later.

\section{P008 A NOVEL STUDY ON NOISE FREQUENCIES IN A GENERAL MEDICINE WARD AT A DISTRICT GENERAL HOSPITAL IN THE UK}

${ }^{1}$ Connor S Qiu*, 'Gazi Sadnan, ${ }^{2}$ Yizhou Yu, ${ }^{1}$ Emmanuel Adebiyi, ${ }^{1}$ Byrone Mitchell, ${ }^{1}$ Darshan Jagannath. 'St Mary's Hospital, Isle of Wight NHS Trust, Newport; ${ }^{2}$ Department of Biology, Imperial College London, London

\subsection{6/bmjresp-2019-bssconf.8}

Introduction Excessive noise levels in the hospital environment is a significant cause of patient and staff dissatisfaction. There are numerous studies on noise levels in hospitals, but noise frequencies in hospitals have been studied to a lesser extent. In this pilot study, we aim to identify the pertinent sound frequencies and decibel levels in a general medicine ward in a district general hospital in the UK.

Methods We deployed an industry standard octave-band noise meter (CEL-620B) to monitor the noise generated in the lobby, a side room and a shared bay of the ward at both day and night over a 1 week period. The meter was set up for continuous recording and the data was subsequently hand-curated to avoid bias from disrupted or tampered recordings.

Results Our results show that hospital noise levels can often exceed $100 \mathrm{~dB}(\mathrm{~A})$; WHO guidelines advise an average of $35 \mathrm{~dB}$ in the day and of $30 \mathrm{~dB}$ at night. ${ }^{1}$ The average peak noise was $119.5 \pm 6.50 \mathrm{~dB}(\mathrm{~A})$. We found that there were higher intensities of noise at lower frequencies as opposed to at higher frequencies (figure 1) and a significant difference between noise intensities at different frequencies (figure 2).

Discussion Noise frequencies from $2000 \mathrm{~Hz}$ to $5000 \mathrm{~Hz}$ may be subjectively perceived to be more unpleasant. ${ }^{2}$ The intensity of noise is also likely detrimental to patient recovery and sleep quality. Our results suggest that hospitals require creative solutions in order to mitigate the adverse effects of noise generated to such specifications.

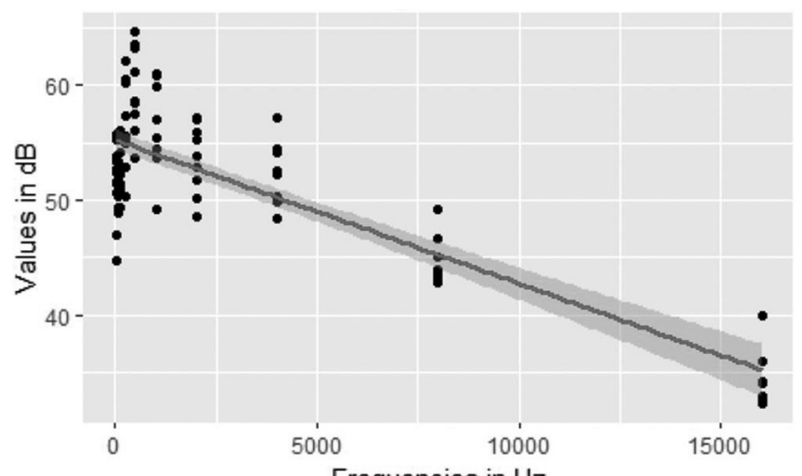

Abstract P008 Figure 1 The frequency level is negatively proportional to the average amount of noise $(p<0.001)$. The poisson and negative binomial models were used to correct for the skewed data distribution

\section{REFERENCES}

1. Berglund B, Lindvall T, Schwela DH. Guidelines for Community Noise. Geneva: World Health Organization; 1999. http://whqlibdoc.who.int/hq/1999/ a68672.pdf

2. Kumar S, von Kriegstein K, Friston K, Griffiths TD. Features versus feelings: dissociable representations of the acoustic features and valence of aversive sounds. Journal of Neuroscience 2012;32(41):14184-14192.

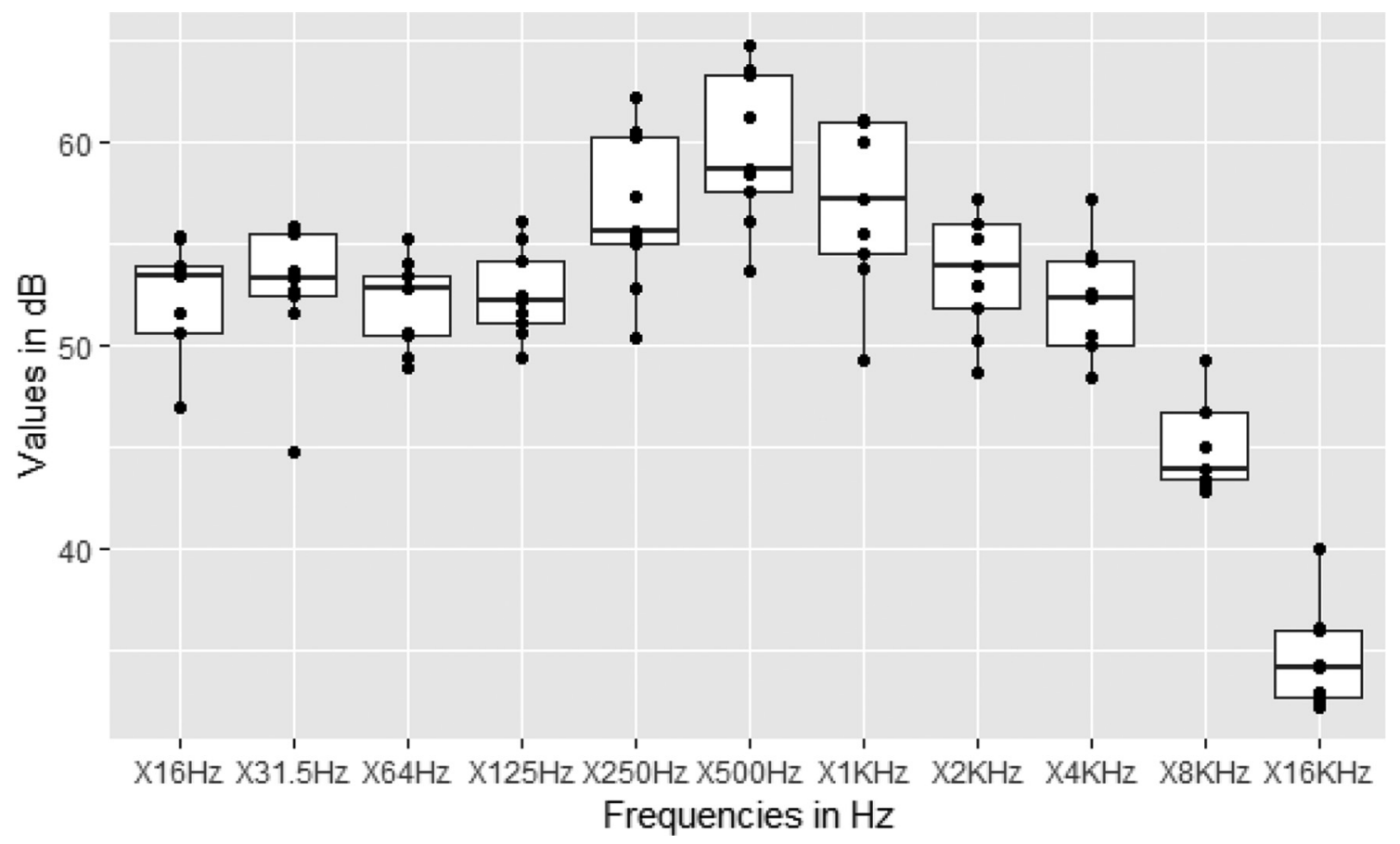

Abstract P008 Figure 2 Distribution of averaged noise across noise meter. We identify a significant difference in the noise intensities across different frequencies (ANOVA, DF $=10, p<0.001$ ) 